\title{
Analisis Miskonsepsi Peserta Didik Menggunakan Certainty of Response Index (CRI) pada Materi Stoikiometri
}

\author{
Wiwiana Wiwiana \\ Pendidikan Kimia, Universitas Negeri Makassar \\ Email: wiwianahamza04@gmail.com \\ Hasri Hasri \\ Pendidikan Kimia, Universitas Negeri Makassar \\ Email: hasriu@unm.ac.id \\ Halimah Husain \\ Pendidikan Kimia, Universitas Negeri Makassar \\ Email: ima_husain@yahoo.com.sg
}

(Diterima: 11-Juli-2020; direvisi: 12-Agustus-2020; dipublikasikan: 16-September-2020)

\begin{abstract}
Abstrak: Banyaknya siswa yang miskonsepsi, maka peneliti melakukan penelitian dengan tujuan untuk menganalisis tingkat pemahaman konsep peserta didik dan faktor-faktor penyebab miskonsepsi peserta didik terhadap materi pokok stoikiometri. Pengumpulan data menggunakan tes diagnostik terbuka dengan skala CRI dengan 18 angka dan wawancara. Hasil penelitian menunjukkan persentase pemahaman konsep $21 \%$ dengan kategori persentase rendah, memahami konsep tetapi tidak yakin sebesar 7\%, dengan kategori rendah, persentase miskonsepsi $12 \%$ dengan kategori rendah dan persentase tidak memahami konsep. $61 \%$ dengan kategori tinggi. Faktor yang menyebabkan miskonsepsi antara lain a) siswa; b) bagaimana mengajar.
\end{abstract}

Kata kunci: Pemahaman Konsep; Stoikiometri; Kepastian Metode Indeks Respon.

Abstract: Many students are misconception, so the researchers do research with the aims to analyze the level of understanding of the participants' concept students and the factors causing students' misconceptions on the subject matter stoichiometry. Data collection uses open-ended diagnostic tests with a scale CRI with 18 numbers and interviews. The results showed the percentage of understanding concepts of $21 \%$ with a low percentage category, understand the concept but not sure at $7 \%$, with the low category, the percentage of misconceptions of $12 \%$ with low categories and percentage do not understand the concept of $61 \%$ with a high category. Factors that cause misconception include a) students; c) how to teach.

Keywords: Understanding Concept; Stoichiometry; Certainty of Response Index Method.

\section{PENDAHULUAN}

Kurikulum 2013 menekankan peserta didik untuk memahami dan menghayati cara memperoleh suatu konsep, mampu menghubungkan suatu konsep dengan konsep yang lain dan mengaplikasikan sebuah konsep untuk menguatkan konsep yang lain. Dengan demikian, pemahaman konsep dalam pembelajaran kimia sangat dibutuhkan untuk menguasai materi secara utuh.

Berdasarkan wawancara yang dilakukan kepada guru SMA Negeri 4 Makassar, bahwa salah satu materi yang sulit dipahami peserta didik adalah materi stoikiometri. Hal ini disebabkan karena pada 
materi stoikiometri memiliki banyak konsep yang saling berhubungan. Beberapa hal yang terjadi pada peserta didik kelas XI adalah sulitnya peserta didik dalam membedakan hukum-hukum dasar kimia, kemampuan peserta didik dalam menghafal sedangkan lemah dalam memahami makna, dan rendahnya kemampuan peserta didik dalam menganalisis masalah yang diberikan oleh guru. Hal ini diakibatkan oleh beberapa faktor diantaranya cara mengajar guru menggunakan model pembelajaran konvensional, kurangnya minat peserta didik dalam mempelajari kimia dan kurangnya usaha peserta didik untuk mengumpulkan data saat proses pembelajaran berlangsung. Masalah yang terjadi pada peserta didik tersebut memungkinkan terjadinya miskonsepsi sebagaimana diungkapkan bahwa penyebab miskonsepsi peserta didik diantaranya faktor guru, lingkungan atau kebiasaan peserta didik, buku teks, metode mengajar, dan diri peserta didik (Suparno, 2005).

Miskonsepsi peserta didik dapat diidentifikasi menggunakan beberapa metode salah satunya menggunakan metode Certainty of Response Index (CRI) (Hakim, 2012). Metode CRI modifikasi dapat mengatasi masalah budaya yang cenderung tidak yakin dengan apa yang peserta didik jawab, dalam metode ini pula memungkinkan peserta didik untuk memberikan alasan atas jawaban yang peserta didik pilih sehingga dapat mengungkapkan letak miskonsepsi peserta didik berdasarkan alasan yang peserta didik tuliskan (Hakim, 2012).

Berdasarkan uraian tersebut diatas, maka peneliti tertarik untuk mengetahui lebih lanjut pemahaman konsep peserta didik kelas XI SMA Negeri 4 Makassar dengan judul penelitian "Analisis Miskonsepsi Peserta Didik Kelas XI SMA Negeri 4 Makassar pada Materi Stoikiometry Menggunakan Certainty of Response Index (CRI)".

Tujuan dari penelitian ini adalah (1) Mengetahui persentase peserta didik kelas XI SMA Negeri 4 Makassar yang paham konsep dengan baik, paham konsep tetapi kurang yakin, miskonsepsi dan tidak paham konsep; (2) mengetahui faktor-faktor yang menyebabkan peserta didik tergolong dalam kategori miskonsepsi pada materi stoikiometri; (3) Mengeahui gambaran miskonsepsi peserta didik pada materi stoikiometri.

\section{METODE}

Penelitian ini termasuk penelitian deskriptif dengan desain penelitian sequential explanatory. Sequential explanatory (disebut juga model dua fasa) terdiri dari pengumpulan data kuantitatif yang dilanjutkan dengan penjelasan data secara kualitatif (Creswell, 2009).

Penelitian dilaksanakan pada Juli Agustus 2019 semester genap tahun ajaran 2018/2019. Lokasi penelitian bertempat di SMA Negeri 4 Makassar yang berlokasi di jalan Cakalang No 3, Totaka, Ujung Tanah, Kota Makassar. Populasi pada penelitian ini adalah peserta didik kelas XI SMA Negeri 4 Makassar tahun ajaran 2018/2019 yang telah mempelajari materi stoikiometri. Sampel penelitian ini yakni kelas XI IPA 6 dengan jumlah 30 orang peserta didik.

\section{Pelaksanaan Penelitian \\ Tahap persiapan}

Pada tahap ini, pertama mengadakan observasi ke sekolah dan berkonsultasi dengan guru bidang studi kimia kelas XI, pembuatan instrumen penelitian dan validasi instrument oleh pakar pendidikan.

\section{Tahap Pelaksanaan Penelitian}

Tes objektif dilakukan diakhir pembelajaran stoikiometri, kemudian dialanjutkan dengan wawancara.

\section{Tahap Akhir Penelitian}

Pada tahap akhir, pertama melakukan analisis data yang dilanjutkan dengan penarikan kesimpulan.

Data dikumpulkan menggunakan tes dan nontes. Untuk tes berupa tes pilihan ganda beralasan terbuka dilengkapi metode CRI (Certainty of Response Index), dan untuk non tes menggunakan metode wawancara. Teknik analisis data dilakukan 
dengan cara menghitung persentase peserta didik pada kategori paham konsep, paham konsep tetapi krang yakin, miskonsepsi dan tidak paham konsep. Adapun kategori tersebut dapat ditentukan berdasarkan Tabel 1 (Hakim, 2012).

Tabel 1. Modifikasi Kategori Tingkatan Pemahaman

\begin{tabular}{cccc}
\hline Jawaban & Alasan & Nilai CRI & Deskripsi \\
\hline Benar & Benar & $>2,5$ & Memahami Konsep dengan Baik \\
Benar & Benar & $<2,5$ & Memahami Konsep Tetapi Kurang Yakin \\
Benar & Salah & $>2,5$ & Miskonsepsi \\
Benar & Salah & $<2,5$ & Tidak Tahu Konsep \\
Salah & Benar & $>2,5$ & Miskonsepsi \\
Salah & Benar & $<2,5$ & Tidak Tahu Konsep \\
Salah & Salah & $>2,5$ & Miskonsepsi \\
Salah & Salah & $<2,5$ & Tidak Tahu Konsep \\
\hline
\end{tabular}

Persamaan untuk mencari persentase peserta didik dalam menjawab soal beserta tingkat keyakinannya adalah sebagai berikut:

$$
\begin{aligned}
& \%=\frac{\text { Jumlah Peserta Didik }}{\text { Jumlah Seluruh Peserta Didik }} \times \mathbf{1 0 0} \% \\
& \text { Kategori } \quad \text { Persentase tingkat } \\
& \begin{array}{l}
\text { pemahaman dapat dikelompokkan } \\
\text { sebagaimana pada Tabel } 2 .
\end{array}
\end{aligned}
$$

Tabel 2. Kategori Persentase Tingkat Pemahaman

\begin{tabular}{cc}
\hline Persentase & Kategori \\
\hline $0-30 \%$ & Rendah \\
$31-60 \%$ & Sedang \\
$61 \%-100 \%$ & Tinggi \\
\hline
\end{tabular}

\section{HASIL DAN PEMBAHASAN}

Berdasarkan hasil tes peserta didik menggunakan Certainty of Response Index (CRI) dengan soal berbentuk pilihan ganda beralasan terbuka, persentase pemahaman peserta didik dikelompokkan dalam kategori paham konsep dengan baik, paham konsep tetapi kurang yakin, miskonsepsi dan tidak paham konsep untuk tiap item soal sebanyak

\begin{tabular}{|c|c|c|c|c|c|c|c|}
\hline \multirow[b]{2}{*}{ No } & \multirow[b]{2}{*}{$\begin{array}{c}\text { Indikator } \\
\text { Pembelajaran Materi } \\
\text { Stoikiometri }\end{array}$} & \multirow[b]{2}{*}{$\begin{array}{c}\text { Nomor } \\
\text { soal }\end{array}$} & \multirow[b]{2}{*}{$\begin{array}{c}\text { Level } \\
\text { kognitif }\end{array}$} & \multicolumn{4}{|c|}{ \% Derajat Pemahaman Peserta Didik } \\
\hline & & & & $\begin{array}{l}\text { Paham } \\
\text { konsep }\end{array}$ & $\begin{array}{c}\text { Paham Konsep } \\
\text { tetapi Kurang } \\
\text { Yakin }\end{array}$ & Miskonsepsi & $\begin{array}{c}\text { Tidak } \\
\text { Paham } \\
\text { Konsep }\end{array}$ \\
\hline \multirow[t]{5}{*}{1} & Menerapkan hukum & 1 & $\mathrm{C} 2$ & $0 \%$ & $0 \%$ & $17 \%$ & $83 \%$ \\
\hline & dasar kimia dalam & 4 & $\mathrm{C} 3$ & $50 \%$ & $20 \%$ & $0 \%$ & $30 \%$ \\
\hline & perhitungan kimia & 13 & $\mathrm{C} 3$ & $50 \%$ & $20 \%$ & $0 \%$ & $30 \%$ \\
\hline & & 14 & $\mathrm{C} 4$ & $0 \%$ & $0 \%$ & $20 \%$ & $80 \%$ \\
\hline & \multicolumn{3}{|c|}{ Rata-rata persentase } & $25 \%$ & $10 \%$ & $9 \%$ & $56 \%$ \\
\hline \multirow[t]{3}{*}{2} & Menjelaskan & 3 & $\mathrm{C} 4$ & $0 \%$ & $0 \%$ & $20 \%$ & $80 \%$ \\
\hline & $\begin{array}{l}\text { bagian-bagian dari } \\
\text { suatu persamaan } \\
\text { reaksi }\end{array}$ & 12 & $\mathrm{C} 4$ & $17 \%$ & $10 \%$ & $13 \%$ & $60 \%$ \\
\hline & \multicolumn{3}{|c|}{ Rata-rata persentase } & $9 \%$ & $5 \%$ & $16 \%$ & $70 \%$ \\
\hline 3 & $\begin{array}{l}\text { Menghitung massa } \\
\text { atom relatif (Ar) }\end{array}$ & 2 & $\mathrm{C} 2$ & $20 \%$ & $0 \%$ & $27 \%$ & $53 \%$ \\
\hline
\end{tabular}
18 item dan tiap indikator dapat dilihat pada Tabel 3.

Tabel 3. Persentase Tingkat Pemahaman Tiap Indikator dan Item Soal 


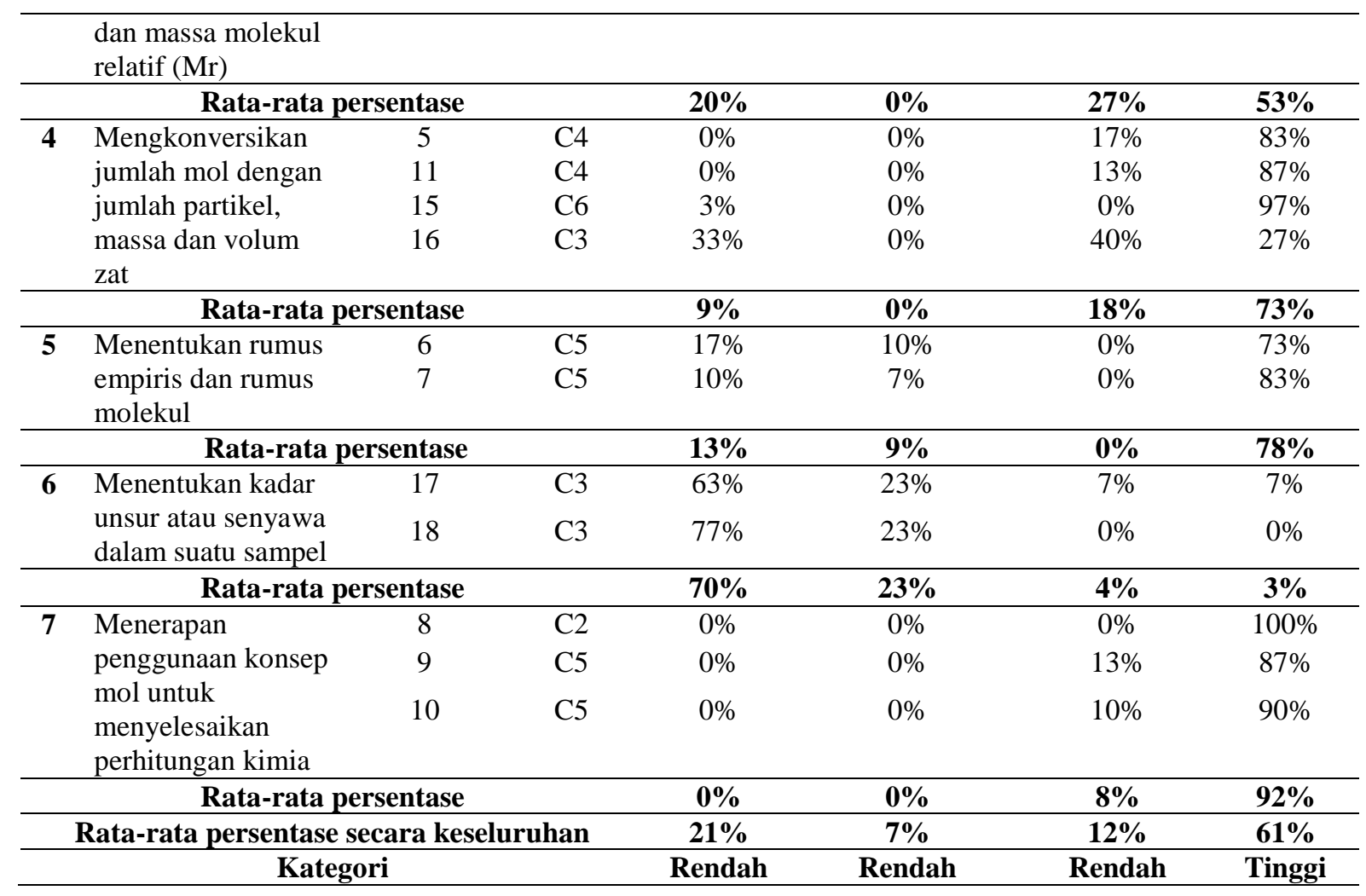

Persentase peserta didik yang paham konsep dengan baik, paham konsep tetapi kurang yakin, miskonsepsi dan tidak paham konsep pada masing-masing level kogtitif dapat dilihat pada Tabel 4.

Tabel 4. Persentase Peserta Didik pada Tingkat Kognitif

\begin{tabular}{cccccc}
\hline \multirow{2}{*}{ No } & Tingkat & \multicolumn{4}{c}{ Tingkat Pemahaman (\%) } \\
\cline { 3 - 6 } & Kognitif & $\mathbf{P}$ & PTY & $\mathbf{M}$ & T \\
\hline 1 & C2 & 23,33 & 6,67 & 14,67 & 55,33 \\
2 & C3 & 44,60 & 13,20 & 9,40 & 32,80 \\
3 & C4 & 3,40 & 2 & 16,60 & 78 \\
4 & C5 & 6,75 & 4,25 & 5,75 & 83,25 \\
5 & C6 & 3 & 0 & 0 & 97 \\
& Rta-rata & 16,22 & 5,22 & 9,28 & 69,28 \\
\hline
\end{tabular}

Gambaran miskonsepsi peserta didik pada indikator pertama yaitu menerapkan hukum dasar kimia dalam perhitungan kimia terjadi pada Hukum Lavoisier dan Hukum Gay Lussac. Miskonsepsi yang terjadi pada Hukum Lavoisier terdapat beberapa kasus diantaranya, pertama peserta didik menyebutkan bahwa Hukum Lavoisier berbunyi "zat sebelum dan sesudah reaksi adalah sama", hal ini keliru, karena jika bunyi Hukum tersebut demikian maka tidak ada reaksi yang terjadi. Sehingga bunyi hukum yang benar adalah "massa zat sebelum dan sesudah reaksi adalah sama". Kedua peseta didik menganggap semua reaksi yang melibatkan Hukum Lavoisier maka semua zat akan habis bereaksi sehingga tidak akan ada yang tersisa. Padahal, pada reaksi kimia tidak selalu massa zat yang bereaksi (reaktan) akan habis seluruhnya menjadi hasil reaksi (produk). Ketiga peserta didik menganggap indeks reaksi merupakan massa reaksi. Sehingga Hukum Lavoisier berlaku ketika indeks reaksi dari pereaksi sama dengan indeks reaksi dari hasil reaksi. Miskonsepsi yang 
terjadi pada Hukum Gay Lussac adalah peserta didik menyelesaikan soal mengenai Hukum Gay Lussac tanpa melibatkan Hukum Gay Lussac sehingga terjadi kekeliruan dalam menjawab. Miskonsepsi yang terjadi pada indikator pertama disebabkan oleh 1) rendahnya kemampuan peserta didik dalam memahami hukum dasar kimia, 2) rendahnya minat belajar peserta didik, 3) mudah menghafalkan namun tidak memahami maknanya, 4) model pembelajaran yang digunakan masih model konvensional.

Gambaran miskonsepsi peserta didik pada indikator kedua yaitu menjelaskan bagian-bagian dari suatu persamaan reaksi, peserta didik menganggap bahwa indeks senyawa sama dengan koefisien reaksi. Adapun konsep yang benar adalah koefisien reaksi pada suatu reaksi menunjukkan banyaknya molekul dalam reaksi tersebut. Miskonsepsi peserta didik pada indikator ke dua dipengaruhi oleh beberapa faktor diantaranya, a) rendahnya kemampuan peserta didik dalam memahami bagianbagian persamaan reaksi, b) rendahnya minat belajar peserta didik, c) model pembelajaran yang digunakan adalah model pembelajaran konvensional.

Gambaran mikonsepsi peserta didik pada indikator ketiga yaitu menghitung massa atom relatif (Ar) dan massa molekul relatif, peserta didik keliru dalam memahami senyawa hidrat sehingga berpengaruh pada saat menentukan $\mathrm{Mr}$ dari senyawa hidrat tersebut. Peserta didik menganggap tanda titik yang memisahkan kedua molekul tersebut berarti kali, sehingga dalam mencari $\mathrm{Mr}$ dari $\mathrm{CuSO}_{4} .5 \mathrm{H}_{2} \mathrm{O}$ dengan mengalikan $\mathrm{Mr} \mathrm{CuSO}_{4}$ dengan $\mathrm{Mr}$ dari $5 \mathrm{H}_{2} \mathrm{O}$. Adapun konsep yang benar bahwa senyawa hidrat adalah senyawa yang mengandung air Kristal sehingga massa molekul senyawa hidrat adalah massa molekul senyawa dijumlahkan dengan massa molekul air kristalnya yang mengikat senyawa tersebut. Faktor-faktor yang mempengaruhi miskonsepsi peserta didik tersebut adalah a) rendahnya kemampuan peserta didik dalam memahami indikator ke tiga, b) rendahnya minat belajar peserta didik, c) model pembelajaran yang digunakan masih model konvensional.

Gambaran miskonsepsi peserta didik pada indikator keempat yaitu mengonversikan jumlah mol dengan jumlah partikel, massa dan volum zat, peserta didik menganggap bahwa massa molekul relatif dipengaruhi oleh senyawa tersebut, padahal massa molekul relative merupakan hasil penjumlahan total dari massa atom relative dari tiap unsur penyusun senyawa tersebut. Faktor-faktor yang mempengaruhi miskonsepsi peserta didik pada indikator keempat adalah, a) rendahnya kemampuan peserta didik dalam memahami konsep dasar dalam hal mengkonversikan jumlah mol dengan jumlah partikel, massa dan volum zat, b) Rendahnya minat belajar peserta didik, c) kemampuan menganalisis peserta didik terbilang rendah, d) peserta didik menghafal rumus yang ada, namun tidak mengetahui kapan rumus tersebut diaplikasikan sehingga peserta didik kesulitan dalam menjawab soal yang diberikan, e) model pembelajaran yang digunakan adalah model pembelajaran konvensional.

Gambaran miskonsepsi peserta didik pada indikator kelima yaitu menentukan rumus empiris dan rumus molekul, peserta didik menganggap bahwa untuk mencari persen massa rumus yang digunakan adalah:

$\%$ massa $=$ massa zat $/$ massa pelarut

Hal ini keliru, karena konsep yang benar bahwa persen massa adalah perbandingan massa zat terlarut dengan massa total larutan dikalikan 100\% (Chang, 2005). Selain itu, peserta didik menjelaskan bahwa $5 \%$ dalam $250 \mathrm{~mL}$ berarti alkohol memiliki jumlah lebih banyak dibanding air. Hal ini keliru karena konsep yang benar bahwa persen volume didefinisikan sebagai perbandingan volume zat terlarut dengan volume total larutan dikalikan $100 \%$ (Syukri, 1999). Sehingga dapat disimpulkan bahwa $5 \%$ alkohol dalam $250 \mathrm{~mL}$ parfum berarti terdapat $12,5 \mathrm{~mL}$ alkohol dalam 250 $\mathrm{mL}$ parfum. Terdapat 2 faktor yang mempegaruhi miskonsepsi peserta didik 
pada indikator ini yaitu a) kesalahan peserta didik dalam memahami konsep larutan, b) rendahnya minat belajar peserta didik, c) model pembelajaran yang diterapkan adalah model pembelajaran konvensional.

Gambaran miskonsepsi peserta didik pada indikator terakhir yaitu menerapkan penggunaan konsep mol untuk menyelesaikan perhitungan kimia, peserta didik keliru memahami pengertian molalitas. Hal ini mengakibatkan salahnya peserta didik dalam menuliskan rumus dari molalitas. peserta didik menganggap bahwa jumlah mol zat terlarut itu dalam 1 gram pelarut murni. Padahal jika ingin menggunakan satuan gram maka setara dengan 1000 gram yang berarti $1 \mathrm{~kg}$ pelarut murni. Miskonsepsi peserta didik yang terjadi pada indikator ini dipengaruhi oleh 5 faktor yaitu, a) rendahnya pemahaman peserta didik akan konsep mol, b) rendahnya minat belajar peserta didik, c) rendahnya kemampuan peserta didik dalam menganalisis soal, d) kemampuan peserta didik dalam menghafalkan rumus tanpa memahaminya, e) model pembelajaran yang diterapkan adalah model pembelajaran konvensional.

\section{SIMPULAN DAN SARAN}

Simpulan yang dapat dikemukakan berdasarkan hasil penelitian dan pengembangan yang telah dilakukan adalah faktor-faktor yang menyebabkan miskonsepsi siswa kelas XI IPA 6 SMA Negeri 4 Makassar pada materi stoikiometri adalah kemampuan peserta didik, rendahnya minat belajar peserta didik, dan caramengajar dalam kelas yang mash menggunakan model konvensional dan terdapat $11,64 \%$ peserta didik yang mengalami miskonsepsi pada materi stoikiometri.

Saran yang dapat dikemukakan adalah Sebaiknya guru bidang studi mencari solusi agar konsep yang dijelaskan dapat tersampaikan kepada peserta didik. Diharapkan kepada peneliti selanjutnya agar dapat mengembangkan instrumen tes untuk semua materi kimia.

\section{DAFTAR RUJUKAN}

Aliefman, H., Liliasari., \& Kadarohman, A. (2012). Student Concept Understanding of Natural Products Chemistry in Primary and Secondary Metabolites Using the Data Collecting Technique of Modified CRI. International Online Journal of Educational Sciences, 4(3).

Chang, R. (2005). Kimia Dasar KonsepKonsep Inti Edisi Ketiga Jilid 1. Jakarta: Erlangga.

Monita, Ade, F., \& Suharto, B. (2016). Identifikasi dan Analisis Miskonsepsi Siswa Menggunakan Three-Tier Multiple Choice Diagnostic Instrument Pada Konsep Kesetimbangan Kimia. Jurnal Inovasi Pendidikan Sains, 7(1).

Suparno. (2005). Miskonsepsi dan Perubahan Konsep dalam Pendidikan Fisika. Jakarta: PT. Grasindo, Cet. I.

Syukri, S. (1999). Kimia Dasar Jilid 2. Bandung: Penerbit ITB. 